\title{
ISOLATION TECHNIQUES OF CONSTRUCTION STRUCTURES AGAINST SEISMIC ACTIONS USING VISCOUS FLUID SYSTEMS
}

\author{
Assistant professor Fănel SCHEAUA, PhD Eng \\ "Dunărea de Jos" University of Galați \\ "MECMET" Research Center
}

\begin{abstract}
The topic of construction structures isolation against earthquakes destructive actions has been regarded as a matter of major importance. Various protection systems have been designed and developed over time in order to be attached to construction structures so as to improve their seismic safety. One isolation method is represented by the use of hydraulic systems aiming to take over and dissipate a part of the earthquake energy so that the dynamic action effect on the structure be greatly diminished. Such a system, called fluidic system because of its fluid dependent operation, is described and analyzed from the operation point of view of in this paper.
\end{abstract}

KEYWORDS: seismic isolation, fluid, dissipative system, three-dimensional modeling, fluid flow analysis

\section{INTRODUCTION}

Insulation systems have been designed in order to achieve the protection of the building structures against the dynamic actions represented mainly by earthquake actions.

Over time, these systems have been constantly modified and adapted to the insulation needs identified at structure type level, so that at present there are very efficient insulation systems which ensure a high degree building stability regarding their height regime and the region in which they are built.

Thus, nowadays different methods of applying the seismic protection on structures can be adopted for both the new buildings and for the rehabilitation of old ones are differentiated.

Such structural protection methods against earthquakes are used both for equipping buildings and for road or railway infrastructure elements represented by bridges or viaducts, which must remain in operation even after the action of an earthquake of considerable magnitude.

This paper presents a mechanical system that operates on the basis of a fluid with special viscosity properties that can be attached to the resistance structure of a construction in order to counteract the destructive effects of earthquakes that may occur in time and require structure in dynamic regime.

It is considered a dissipative hydraulic system attached to isolated structure being positioned between two distinct structural frames providing the possibility to reduce the relative movement between them, thus ensuring an energy consumption which involves taking over a significant amount of the earthquake energy that is consumed and converted to heat at the basic unit level of the system. 
Modeling aspects of the hydraulic dissipative system assembly are presented, as well as a numerical analysis of the working fluid flow inside the device body, in case of a high viscosity silicone oil used as working fluid.

\section{DESCRIPTION HYDRAULIC SYSTEM}

\section{OF THE DISIPPATION}

The hydraulic dissipation system main assembly consists mainly of a cylinder with piston. The cylinder enclosure is filled with working fluid, which can be a synthetic oil, silicone oil or other fluid that has special viscosity properties.

The piston head has a set of passage orifices made internally that allow flow fluid from one side of the cylinder to the other, so that the piston has the possibility to perform translational movement inside the cylinder, forcing the fluid to pass through the orifices.

A rod is attached to the piston so that the two ends of the dissipating device can be connected to the insulated structure elements.

Due to its special construction, the hydraulic dissipative system can ensure a relative axial displacement of the two ends connected to the insulated structure, only by the forced circulation of the working fluid inside the cylinder.

This device is a velocity dependent device whose operation is strongly nonlinear.

Due to the fact that this hydraulic device works without a control device, it is considered a passive seismic isolation system, but there are constructive variants providing the control possibility on the fluid flow rate and with the working pressure values considered as active systems. These active devices operate on the basis of electronic monitoring systems that have the possibility of permanently adjusting the working parameters according to the earthquake magnitude, thus ensuring different dissipation stages of the hydraulic dissipative system.

\section{MODELING ELEMENTS FOR THE HYDRAULIC DISSIPATION SYSTEM ASSEMBLY}

The hydraulic dissipative system represents a mechanical system that by mounting to the resistance structure of a building acts to reduce the effects of seismic actions. For the overall 3D model of a hydraulic dissipation system, the Solid Edge V20 software was used.
The main component elements are assembled being represented by the device cylinder, the piston united with the rod, as well as the fastening elements to the insulated structure.

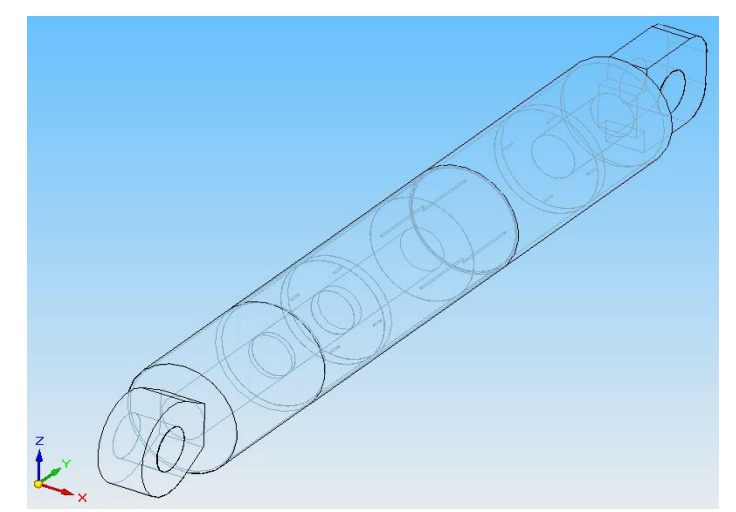

Fig. 2.1. Model of hydraulic dissipation system assembly

The main dimensions of the hydraulic dissipation assembly are presented: total length of the cylinder $1255 \mathrm{~mm}$, mounting length 1458 $\mathrm{mm}$, piston diameter $190 \mathrm{~mm}$, rod diameter 80 $\mathrm{mm}$, total piston stroke $475 \mathrm{~mm}$.

The modality of mounting to the isolated structure is achieved by connecting the two device ends to two different structural elements that would have the relative movement tendency during an earthquake.

An earthquake causes the dissipative device to act in response to repeated tractioncompression movements, causing the piston to move axially through the fluid medium.

Due to the high viscosity of the working fluid that has to pass through the small diameter orifices, a resistance force is formed at the device stem which causes the relative movement, as a damping effect between the structural frames where the protective device is mounted.

\section{WORKING FLUID FLOW ANALYSIS ON THE VIRTUAL MODEL}

The operation of a seismic energy dissipative hydraulic device is based on the properties of the working fluid that is present in the cylinder enclosure.

In order to carry out the translation displacement imposed by the dynamic action that appears at one point in time, the piston must perform an axial motion through the fluid region forcing the fluid to pass through the small diameter orifices. 
Due to the viscosity and compressibility properties of the working fluid, viscous frictional forces are formed at the molecular level which, in addition, ensure a resistant force. By this resistance action, the piston movement opposition is ensured, thus avoiding the relative movement of the device ends.

In order to highlight these operating aspects of the fluid dissipative device, a numerical flow analysis of the working fluid made on the virtual model was performed using the ANSYS CFX program.

The overall three-dimensional model whose dimensions are presented in the foregoing, is introduced in the analysis having declared the fluid region inside the cylinder, the working fluid being 125 Stokes cinematic viscosity silicone oil, having a density of $975 \mathrm{~kg} / \mathrm{m} 3$.

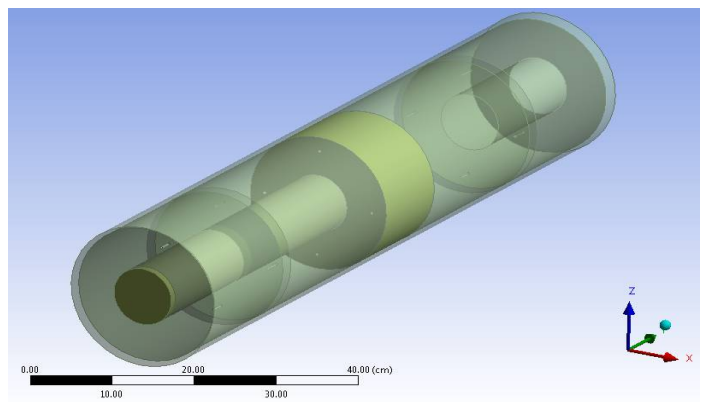

Fig. 4.1. Model of hydraulic dissipation device assembly introduced in the analysis with Ansys CFX

For the ensemble model introduced in the numerical analysis (figure 4.1), a mesh network with tetrahedral form elements having a number of 381,449 nodes and 2,032,992 elements is realized.

For the initial data of the analysis were declared the main domains represented by the device cylinder being declared as solid, material steel, the fluid region (silicone oil) positioned inside the cylinder enclosure and the solid domain immersed within the fluid region represented by the piston, whose material is also steel.

To perform the simulation of the real operating conditions of the hydraulic dissipation device, a value for piston velocity movement of the device of $30 \mathrm{~mm} / \mathrm{s}$ in axial direction is declared, which describes the entry into action of the protective system, when an earthquake occurs.

The results obtained from the analysis are presented in terms of fluid velocity and pressure but also specific turbulences recorded at the fluid region level (Figure 4.2).

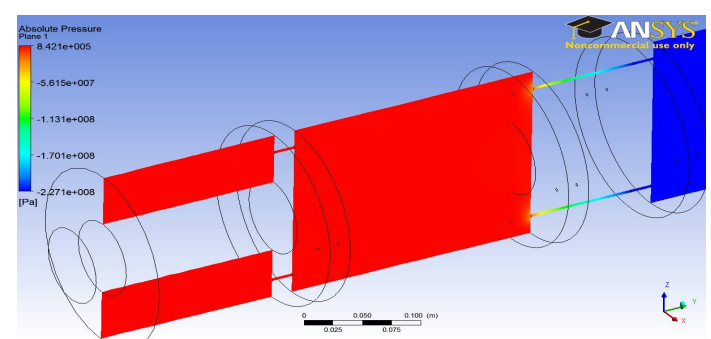

a) Absolute pressure values $(\mathrm{Pa})$

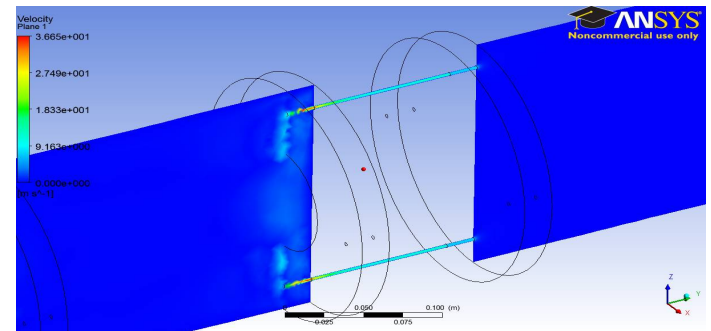

b) Fluid velocity values $(\mathrm{m} / \mathrm{s})$

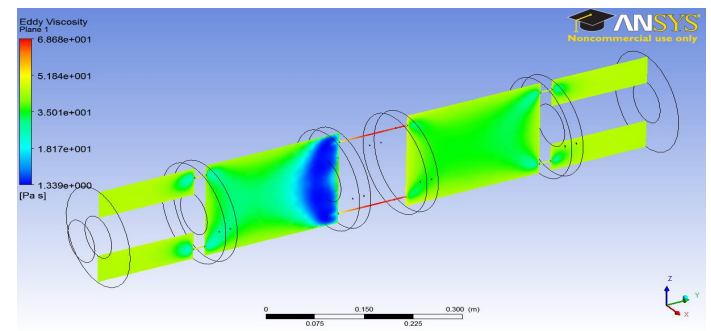

c) Values for turbulence recorded at the fluid region level due to dynamic viscosity ( $\mathrm{Pa} \mathrm{s}$ )

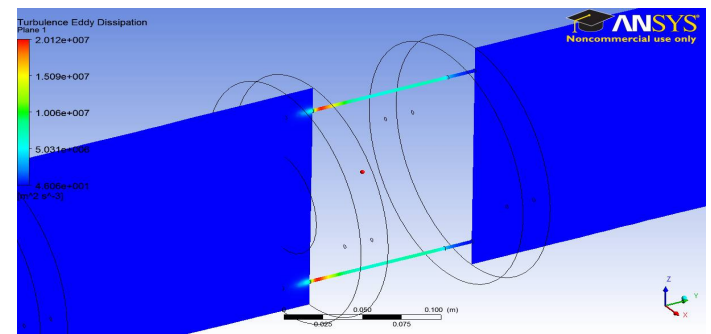

d) Values of turbulence dissipation rate inside the fluid region $(\mathrm{m} 2 / \mathrm{s} 3)$

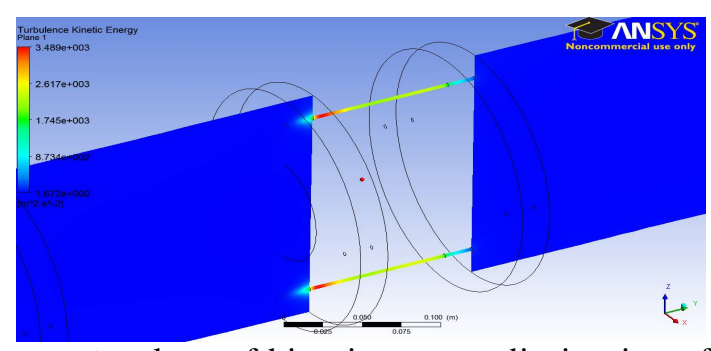

e) values of kinetic energy dissipation of turbulences created at the fluid region level $(\mathrm{m} 2 / \mathrm{s} 2)$

Fig. 4.2. Results recorded from fluid flow analysis

The obtained results show the increase of the pressure values in the cylinder chamber inside the fluid region required for compression according with the piston movement tendency 
(figure 4.2. a).

High fluid flow velocity values are recorded at the circular orifices level which allow the fluid to be transferred from one chamber of the cylinder to another (Figure 4.2. b) as the piston is moved in the axial direction.

The turbulence values recorded inside the analyzed fluid region due to the dynamic viscosity of the working fluid are also highlighted (figure 4.2. c), but also higher turbulence dissipation values are recorded inside the flow orifices due to the viscosity and kinetic energy efforts (Figure 4.2. $\mathrm{d}$ and e).

For the analyzed model, the resistance strength at the calculated hydraulic dissipative device stem is $2385 \mathrm{daN}$.

This force value represents the response of the protection system to the dynamic action that requires the isolated structure at a given moment in time, having a role in reducing the relative displacements between the structural frames where it is mounted.

Different resistant force values can be provided by changing the value of the diameter of the circulating orifices located inside the piston head, but also by using a working fluid with different viscosity properties.

For each application, the specific operating conditions must be studied and the proper dimensioned dissipation device model attached to the building structure will be used.

\section{CONCLUSION}

The earthquake safety methods used today in the construction field have evolved over time through the development of protective devices that can ensure an optimal level of safety not only for new construction structures but also for the rehabilitation of old ones.

The use of these protection devices made it possible to carry out large projects in the field of civil engineering regarding the height regime, but also from the point of view of the objective location in areas with intense seismic activity.

Such a device intended for protection against the earthquake dynamically destructive actions was presented in this work and it was analyzed from the viewpoint of the operating principle.

It is a hydraulic dissipation device that works on the passive principle (without having control devices attached), being a constructive variant that can represent the optimal solution to be applied for the building structures seismic isolation represented by buildings and road and railway infrastructure elements represented by bridges or viaducts.
On the analyzed virtual model from the working fluid flow point of view, the recorded values for the fluid pressure and circulation velocity were highlighted, together with turbulence and dissipation rates values which are the result of the viscosity efforts and kinetic energy at the fluid region level.

Being a protective energy dissipation device, whose operation is velocity dependent, the total force value at the piston stem (2385 daN) was calculated, representing the device response to the need described in the initial conditions of the piston displacement analysis at $10 \mathrm{~cm} / \mathrm{s}$ velocity simulating the occurrence of an earthquake.

By means of the numerical analysis of the working fluid flow on the overall device virtual model, the preliminary necessary information for the design engineer of such devices regarding the values of the parameters involved in operation is ensured, and also different types of fluids that can be taken into account to be used are tested.

The main advantages of using this kind of fluid dissipation systems is that they operate on a passive principle and the production costs are lower in comparison with the active control devices.

Also, the installation and maintenance work on site of the insulated structure does not present major difficulties to be achieved.

\section{REFERENCES}

[1] Axinti S., Scheaua F. D., "Introducere în hidraulica industrială”, ISBN 978-606-696-032-8, Editura Galati University Press, Galati 2015

[2] Axinti G., Axinti A. S., "Acţionări hidraulice şi pneumatice", Vol I-V, Aditura Tehnica-Info, Chişinău, 2008-2012

[3] Scheaua, F., D., Description of a Composed Seismic Isolation System for Bridge Structures, Analele Universităţii "Eftimie Murgu" Reşiţa, anul XXII, nr. 2, ISSN 1453 - 7397, 2015, Reşiţa, România

[4] Scheaua, F., D., Analiza comportarii sistemelor de disipare cu frecare uscată la acțiuni dinamice, Teza de doctorat, Univ Dunarea de Jos din Galaţi, 2013, Galaţi, România

[5] Scheaua, F., D., Special pattern of hydraulic dissipation system used for isolation of bridges against earthquakes, Analele Universităţii „Eftimie Murgu” Reşiţa, anul XXIV, nr. 1, 2017, Reşiţa, România

[6] http://www.clearcoproducts.com/silicone/Standar d Viscosity.pdf 